\title{
Genetic determinism of anatomical and hydraulic traits within an apple progeny
}

\author{
PIERRE-ÉRIC LAURI ${ }^{1}$, OLIVIER GORZA ${ }^{1}$, HERVÉ COCHARD $^{2}$, SÉBASTIEN MARTINEZ $^{1}$, JEAN-MARC CELTON $^{1}$, \\ VÉRONIQUE RIPETTI ${ }^{1}$, MARC LARTAUD ${ }^{3}$, XAVIER BRY $^{4}$, CATHERINE TROTTIER $^{4} \&$ EVELYNE COSTES $^{1}$
}

${ }^{1}$ INRA, UMR 1334 AGAP, F-34398 Montpellier Cedex 5, France, ${ }^{2}$ INRA, UMR 547 PIAF, F-63100 Clermont-Ferrand, France, ${ }^{3}$ CIRAD, UMR 1334 AGAP, F-34398 Montpellier Cedex 5, France and ${ }^{4}$ Université Montpellier II, UMR I3M, F-34095 Montpellier Cedex 5, France

\begin{abstract}
The apple tree is known to have an isohydric behaviour, maintaining rather constant leaf water potential in soil with low water status and/or under high evaporative demand. However, little is known on the xylem water transport from roots to leaves from the two perspectives of efficiency and safety, and on its genetic variability. We analysed 16 traits related to hydraulic efficiency and safety, and anatomical traits in apple stems, and the relationships between them. Most variables were found heritable, and we investigated the determinism underlying their genetic control through a quantitative trait loci (QTL) analysis on 90 genotypes from the same progeny. Principal component analysis (PCA) revealed that all traits related to efficiency, whether hydraulic conductivity, vessel number and area or wood area, were included in the first PC, whereas the second PC included the safety variables, thus confirming the absence of tradeoff between these two sets of traits. Our results demonstrated that clustered variables were characterized by common genomic regions. Together with previous results on the same progeny, our study substantiated that hydraulic efficiency traits co-localized with traits identified for tree growth and fruit production.
\end{abstract}

Key-words: Malus domestica; cavitation; heritability; hydraulic conductivity; pith area; QTL; wood area; xylem efficiency; xylem safety; xylem vessel.

\section{INTRODUCTION}

From a xylem hydraulic perspective, the global performance of a plant relies on two main characteristics: efficiency (i.e. volume flow rate per pressure gradient) and safety (i.e. the ability to transport sap on a long distance and in a large range of environmental conditions). Because xylem sap is transported from roots to leaves under negative pressure, it is susceptible to cavitation events (i.e. the transition from liquid water to stable vapour phase). The most relevant estimator of cavitation is the degree of embolism which is directly related to the amount of blockage of xylem sap transport in vessels caused by air bubbles (Sperry

Correspondance: P-É. Lauri.E-mail: lauri@supagro.inra.fr
\& Tyree 1988; Tyree \& Ewers 1991; Cochard et al. 2010). The xylem safety of a stem is assessed through the curve, called the vulnerability curve (VC), relating water potential $(P$, $\mathrm{MPa}$ ) and the loss of hydraulic conductivity (PLC, \%). Two parameters are used to summarize the sigmoid-type curve that is usually obtained: the value at which $50 \%$ of the conductivity is lost $\left(P_{50}\right)$ and the slope of the curve at this point (Cruiziat, Cochard \& Améglio 2002). A high hydraulic safety (i.e. low negative values of $P_{50}$ ) means high resistance to cavitation and, therefore, to embolism. It is established that resistance to cavitation is positively related to resistance to drought (Sperry \& Tyree 1988; Maherali, Pockman \& Jackson 2004; Cochard et al. 2008; Blackman, Brodribb \& Jordan 2010), even though there is still a gap between our knowledge on experimentally induced cavitation and plant adaptation to drought (Brodribb et al. 2010).

There is a positive relationship between high growth potential at shoot and tree levels, and the following two traits: xylem axial conductivity (i.e. volume flow rate per pressure gradient per length) (Iwanami, Moriya \& Abe 2009; Tombesi et al. 2010) and xylem vessel lumen area (Atkinson et al. 2003; Sellin, Rohejärv \& Rahi 2008; Russo et al. 2010; Tombesi et al. 2010). These relationships are easily explained by the Hagen-Poiseuille law stating that xylem hydraulic conductivity increases with the fourth power of vessel radius (Tyree \& Sperry 1989; Tyree, Davis \& Cochard 1994; Cruiziat et al. 2002; Lemoine, Jacquemin \& Granier 2002; Knoblauch \& Peters 2010). Complementing these results at within-stem level, it has been shown that xylem conductance at the junction between the stem and the axillary bud is positively related to the size and the number of appendages of this axillary bud (Cochard et al. 2005a; Lauri et al.2008). On the other hand, the relationship between xylem anatomy and xylem safety is more controversial, and although vessel diameter is positively related to frost-induced embolism, the relationship between vessel diameter and drought induced-embolism is much weaker (Tyree et al.1994). Indeed, depending on studies, there is a negative (Lemoine et al. 2002; Hacke, Jacobsen \& Pratt 2009), a positive (Cai \& Tyree 2010; Markesteijn et al. 2011) or even no consistent (Rosner et al. 2007; Willson, Manos \& Jackson 2008; Fichot et al. 2010; Schreiber et al. 2011) relationship between vessel diameter or transport efficiency 
and vulnerability to embolism. It has been shown that drought-induced embolism is in fact more related to vessel wall structure, that is, inter-vessel wall thickness (Cochard et al. 2008; Fichot et al. 2010), pit pore and pit membrane area, and pit membrane porosity (Tyree \& Sperry 1989; Hacke et al. 2001; Lemoine et al. 2002; Choat, Cobb \& Jansen 2008; Chen et al. 2009; Cochard et al. 2009; Hacke et al. 2009; Cai \& Tyree 2010). The weak overlapping between xylem anatomical features underlying efficiency and safety is likely to explain why a lack of trade-off between xylem efficiency and xylem safety is often shown (Willson et al. 2008). The finding that calcium is a major determinant of between-species differences in vulnerability to cavitation without effects on xylem efficiency brings more support to this idea (Sperry \& Tyree 1988; Herbette \& Cochard 2010).

Most of the studies on hydraulics and related anatomical features in perennials were carried out across a small number of taxa at various orders (e.g. family, genera, species or clones; Rosner et al.2007; Cochard et al.2008; Fichot et al. 2010), possibly including different ecological groups (e.g. shade-tolerant species versus pioneers; Markesteijn et al. 2011). Furthermore, although cavitation resistance has been widely investigated across species (Brodribb et al. 2010; Fichot et al. 2010), there are only a few studies comparing closely related genotypes (Sangsing et al. 2004; Cochard, Casella \& Mencuccini 2007). There is still a lack of studies assessing the genetic determinism of hydraulic and related anatomical traits in genotypes with the same parentage. Understanding the genetic determinisms of complex traits can be carried out through quantitative genetic studies that aim at analyzing the trait variability and estimating the expected genetic improvement (Hill 1971; Gallais 1990). For this purpose, the concept of heritability has been introduced (Hanson 1963; Falconer 1981). Moreover, the mapping of quantitative trait loci (QTL) is a key tool that has been widely used to detect the genomic regions that control variation in quantitative traits. However, both accurate heritability estimates and QTL detection require the phenotyping of a large number of individuals (Yao \& Mehlenbacher 2000; Liebhard et al. 2003). Despite this methodological constraint, this approach has been used in perennials, on both forest (e.g. Scotti-Saintagne et al. 2004) and fruit trees. In the latter case, several studies have been developed in the apple, for example, to characterize the genetic determinism of quantitative traits such as disease resistance (Calenge \& Durel 2006; Soufflet-Freslon et al. 2008) or tree growth and branching (Conner, Brown \& Weeden 1998; Liebhard et al. 2003; Kenis \& Keulemans 2007; Segura et al. 2007, 2008).

The domesticated apple, Malus domestica, was chosen for this study. Originating from the mountainous regions of central Asia with a continental climate (Harris, Robinson \& Juniper 2002), it has a worldwide geographical and climatic distribution from high elevations in the equatorial climate (Janick 1974) to high latitudes in Europe and North America (Luby 2003). Although most of the apple production comes from temperate climate, apple is also cultivated in semi-arid regions where irrigation is crucial (Webster 2005). The adaptation of apples to drought is likely to be a main challenge genetics and breeding will have to face. This issue can be addressed through a better understanding of water transport and use at two different and complementary levels: hydraulic conductance at stem level and stomatal conductance at leaf level (Sperry, Alder \& Eastlack 1993; Cruiziat et al. 2002; Chen et al. 2009). A recent study developed on an apple progeny shows that stomatal conductance strongly decreases with increased vapour pressure deficit (VPD) with high broad-sense heritability for this trait (Regnard et al.2009). These results agree with the fact that apples are classified as isohydric, with an early stomatal closure maintaining high leaf water potential in trees growing in soil with low water status and/or under high evaporative demand (Parent et al. 2010).

Our aims were to extend these preliminary results, and to analyse the xylem water transport efficiency and cavitation resistance, encompassing anatomical and hydraulic traits, across genotypes belonging to the same apple progeny as the one studied by Regnard et al. (2009). Our study focused on two points:(1) the relationship between xylem efficiency and xylem safety, and the possibility that some genotypes expressed both an efficient and a safe xylem hydraulic system; and (2) the broad-sense heritability of the studied traits and their genetic determinism through a QTL analysis.

\section{MATERIALS AND METHODS}

\section{Study area and plant material}

The studied apple progeny was derived from a 'Starkrimson' $\times$ 'Granny Smith' cross characterized by a strong variability of tree vigour and architectural traits (Segura et al. 2006, 2007; Segura, Cilas \& Costes 2008). In March 2004, 123 own-rooted trees issued from cuttings, one tree per genotype, were randomly planted among trees belonging to other progenies at the Melgueil INRA Montpellier Experimental Station (south-east of France, $43^{\circ} 37 \mathrm{~N}$, $03^{\circ} 52 \mathrm{E}$ ). Plantation distances were $5 \mathrm{~m}$ between the rows and $1.5 \mathrm{~m}$ within the row with an east-west row orientation. Trees were minimally pruned during the whole trial, except in winter 2008-2009 to promote growth of new shoots convenient for hydraulic studies. Irrigation and fertilization scheduling, as well as pest and disease control, were carried out by conventional means in line with professional practices in the region. In February 2010, 90 7-year-old trees, one tree per genotype, were chosen based on their good health and having 2009 annual stem length compatible with the cavitron technique (i.e. annual stem equal or longer than $40 \mathrm{~cm}$ ) (see below). All sampled stems were in horizontal to upright position on the south-oriented face of the trees.

\section{Xylem conductivity and wood anatomy}

Four c. 40-cm-long, 1-year-old stems per tree/genotype were sampled between the 5th and 10th of February 2010, and immediately wrapped in a black plastic bag with moist 
(a)

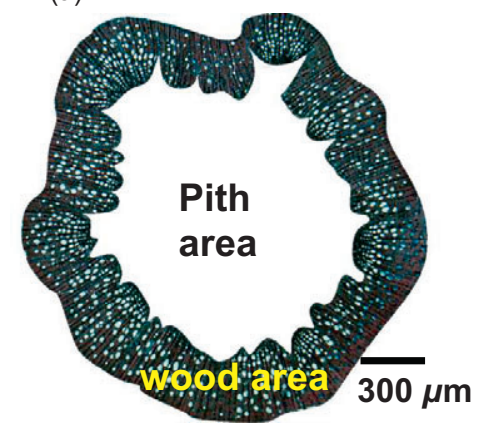

(b) Cortex-wood limit

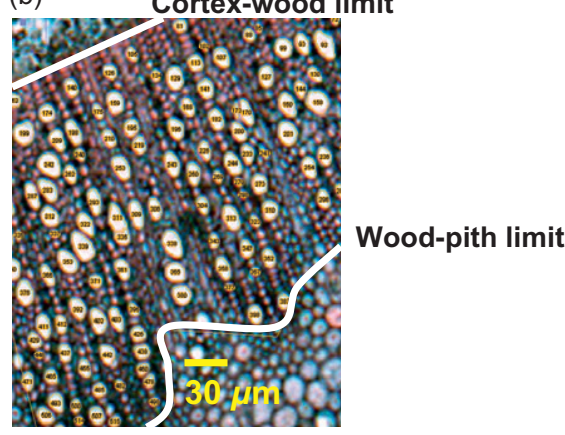

Figure 1. Silhouette of wood area of an entire 1-year-old apple stem cross-section (a), and detailed view of a wood portion showing cortex (outward)-wood and wood-pith (inward) limits, and numbering (using ImageJ freeware) of individual vessels (b). paper towels to minimize dehydration and brought to a cold chamber at $5{ }^{\circ} \mathrm{C}$. Prior to measurement, each stem was cut again at the bottom end so as to have exactly a length of $36 \mathrm{~cm}$. The bottom and top diameters of the sampled stems (BD and TD, respectively) were then measured. The stem hydraulic conductivity $\left(K_{\mathrm{h}} ; \mathrm{mmol} \mathrm{s} \mathrm{MPa}^{-1} \mathrm{~m}\right.$; Tyree \& Ewers 1991) was measured using the high-pressure flow meter (HPFM; Dynamax, Houston,TX, USA;Tsuda \& Tyree 2000) apparatus, which is based on the perfusion of deionized and filtered water at a given pressure at the bottom of the cut stem $(P, \mathrm{MPa})$ and measurement of the rate of water exudation $\left(F, \mathrm{mmol} \mathrm{s}^{-1}\right)$ at the top end. Water exudation was measured using a $50 \mathrm{~mL}$ beaker applied for $1 \mathrm{~min}$ to the cut top-end surface. The difference in beaker weight, to the nearest tenth of a milligram, before and after measurement gave the amount of water exuded. Once $K_{\mathrm{h}}$ was measured, the longest internode at the top of each stem was cut and immediately put in glutaraldehyde-paraformaldehydecaffeine (GPC) fixative for $24 \mathrm{~h}$. It was then dehydrated in a graded ethanol series and eventually kept in $70 \%$ alcohol in a $2 \mathrm{~mL}$ safe-lock Eppendorf tube (http://www.eppendorf. com/int/) for later anatomical investigations. The stem anatomical analysis was carried out on the entire crosssection area of the middle part of each internode. Then, $15-\mu \mathrm{m}$-thick slides were cut using a hand vibratom HM $650 \mathrm{~V}$ (Microm) (http://www.microm-online.com/). Slides were stained with safranin and Alcian blue (FASGA), which permitted to separate unlignified tissues (blue) from lignified ones (red). Prepared slides were observed with a light DM4500 microscope (Leica, Wetzlar, Germany) at up to $5 \times 1$ magnification, coupled with a Retiga 2000R Qimaging (Retiga, Surrey, Canada) digital camera using Velocity Acquisition 5.3.1 software (http://www.velocity-software. $\mathrm{com} /$ ). When the cross-section was too large for a single photograph, several photographs were taken and assembled using Microsoft image composite editor 1.3.4. Image analysis was performed using the open-source ImageJ freeware (http://rsbweb.nih.gov/ij/download.html; Ferreira \& Rasband 2010). The following values were calculated from the image: number and total area of xylem vessel lumen (VN and VA, respectively), wood area (WA) and pith area (PA; Fig. 1).

Three variables were computed from the previous ones: ratio of $K_{\mathrm{h}}$ to total xylem vessel area (VA) [i.e. hydraulic specific conductivity $\left(K_{\mathrm{hs}}\right)$ ], proportion of wood area (WA) among wood and pith area (PA) (WAprop) and number of vessels (VN) per unit of wood area (WA) [i.e. vessel density (VD)]. Moreover, to get a more accurate view of the distribution of vessel cross-section areas across genotypes the numbers and proportions of vessels in two extreme cross-section area categories, narrow and large, were computed as follows. The values of vessel area corresponding to the upper limits of the first, second and third quartiles were determined over the whole database. They yielded to the following values: 44,79 and $120 \mu \mathrm{m}^{2}$, respectively. These threshold values were then applied to each individual image and the proportion of vessels within quartile 1 (PVQ1; from the minimal size value chosen in our study 21.5 to $44 \mu \mathrm{m}^{2}$ ) and quartile 4 (PVQ4; from 120 to $600 \mu \mathrm{m}^{2}$ this latter value being the maximum vessel area observed) were computed. For better legibility in the following, PVQ1 and PVQ4 will be termed proportion of small and large vessels, respectively. In c. $75 \%$ of the slides, an average of 1/10th of wood area staining was insufficiently rinsed out, leading to inaccurate counting of vessel and measurement of vessel area. In this case, the mean number of vessel and vessel area of this part were then estimated by inference from the remaining part of the wood section from the same slide.

Two theoretical variables were computed from these anatomical data. The hydraulic vessel diameter

$D_{\mathrm{h}}=\frac{\sum_{\mathrm{i}=1}^{\mathrm{i}=\mathrm{n}} d^{5}}{\sum_{\mathrm{i}=1}^{\mathrm{i}=\mathrm{n}} d^{4}}(\mu \mathrm{m})$

where $d$ is the diameter of one vessel (considering the vessel cross-section as a circle) which aims to take into account the fact that large vessels are more conductive than narrow vessels (Tyree \& Zimmermann 2002). The theoretical xylem hydraulic conductivity $\left(K_{\mathrm{ht}}, \mathrm{mmol} \mathrm{s}{ }^{-1} \mathrm{MPa}^{-1} \mathrm{~m}\right)$ based on the Hagen-Poiseuille law for ideal capillaries of circle crosssection and assuming laminar flow,

$$
K_{\mathrm{ht}}=\sum_{\mathrm{i}=1}^{\mathrm{i}=\mathrm{n}} \frac{\pi d^{4} \eta}{128} L,
$$


where $d$ is vessel diameter, and $\eta$ is viscosity of the solution in the vessels at $20^{\circ} \mathrm{C}\left(1.002 \times 10^{-9} \mathrm{MPa}\right)$ (Tyree \& Zimmermann 2002; Cai \& Tyree 2010).

\section{Vulnerability to cavitation}

Vulnerability to cavitation was determined on another set of two to four stems per tree sampled at once in the end of April 2010. Stems were analogous to the ones sampled for the conductivity experiment and were stored in the same way. Cavitation measurements spread over 4 weeks beginning the day of sampling and were done each consecutive day on randomly chosen stems. There was no significant drift with time of the slope and $P_{50}$ confirming recent findings by Herbette et al. (2010) on beech showing that stem segments stored for up to 10 weeks at $5{ }^{\circ} \mathrm{C}$ in humid dark conditions were still suitable for $P_{50}$ determination. Xylem cavitation was assessed with the Cavitron technique (Cochard et al. 2005b). The principle of the technique is to use centrifugal force to increase the water tension in the stem segment and, at the same time, to measure the decrease of its hydraulic conductance. This technique is reliable only if vessels are shorter than the sample length to avoid vessels open at both ends. To assess this, we used the air infiltration technique (Cochard et al.2010). One extremity of each stem was immersed in water, and the other extremity was infiltrated with compressed air (0.15 MPa). In the case vessels were open at both ends, air bubbles were released in the water. In almost all cases, there were no or only a few vessels open, confirming the 36-cm-long stem was convenient for the apple. The VC was computed as follows. The maximum sample conductivity $\left(K_{\max }\right)$ was first measured at low speed and high pressure $(-0.1 \mathrm{MPa})$. Xylem pressure was then lowered stepwise by increasing the rotational velocity, and $K$ was determined anew. Each value was the mean or three batches of five measurements each. Sample loss of conductivity (\%) was computed as:

$\mathrm{PLC}=100 \times 1-\frac{K}{K_{\max }}$,

The observed curve was then fitted to a sigmoid curve using the Excel software solver:

PLC $=\frac{100}{\left(1+\exp ^{\frac{\text { slope }}{25 \times \mathrm{P}-\mathrm{P}_{50}}}\right)}$,

$P_{50}$ (expressed here as a tension, $\mathrm{MPa}$ ) and the slope (SL, \% $\mathrm{MPa}$ ) were determined from the fitted sigmoid curve. Variables with abbreviations and formula are detailed in Table 1.

\section{Data analysis}

Data were analysed in the following two steps.

Firstly, broad sense heritability of phenotypic means $\left(h^{2}\right.$ b) was estimated as $\sigma^{2} G /\left[\sigma^{2} G+\left(\sigma^{2} e / n\right)\right]$, where $\sigma^{2} G$ and $\sigma^{2} e$ are the genotypic and residual variances, respectively, and $n$ is the mean number of stems (two to four per tree/genotype depending on the variable). $h^{2}{ }_{\mathrm{b}}$ was derived from the $F$-value in the one-way analysis of variance (ANOVA) as $1-(1 / F)$ (Gallais 1990). The associated confidence interval (CI) was calculated according to Knapp, Stroup \& Ross (1985) with the lower and upper limits equal to $[1-1 /$ $\left.\left(F_{\text {obs }} \cdot F_{0.975}\right)\right]$ and $\left[1-1 /\left(F_{\text {obs }} \cdot F_{0.025}\right)\right]$, respectively. The ANOVA model for unbalanced data (type III) was performed using the $\mathrm{R}$ freeware, version 2.7.2 (http:// www.rproject.org) with package 'car'. A variable was considered heritable when the lower limit of the CI of $h^{2}$ b was positive.

Secondly, the distribution of genotypes (one average value per genotype) in the space of the heritable variables was investigated through a principal component analysis (PCA). To avoid the overweighting of bundles containing many correlated (positively or negatively) variables, which may bias PCA analyses, the following procedure was developed. A clustering analysis was first carried out on the sine ${ }^{2}$ (i.e. $1-R^{2}$ ) distance matrix between the variables with the agglomeration method 'average'. The sine ${ }^{2}$ is being used in order to account for the variable directions only. Indeed, two highly correlated variables, positively or negatively ( $R$ reaching +1 or -1 , respectively), will thus have a short distance between them $\left[\operatorname{sine}^{2}(-1)=\operatorname{sine}^{2}(+1)=0\right]$, whereas two low correlated variables ( $R$ reaching 0$)$ will be separated by the maximum distance $\left[\operatorname{sine}^{2}(0)=1\right]$. A PCA was then carried out within each group of clustered variables so as to determine a new synthetic variable estimated by the first principal component. We considered that this new variable was well representative of the cluster when the principal component of this cluster was taking into account a minimum of $75 \%$ of the total variance. Eventually, a new PCA was carried out on the synthetic variables. All analyses were performed using $\mathrm{R}$ freeware version 2.7 .2 (http:// www.rproject.org) with packages 'car', 'cluster' and 'HSAUR' to compute the correlation matrix, clustering analysis and PCAs, respectively.

\section{Genetic map and QTL detection}

QTL detection was performed using a genetic map developed by Segura etal. (2007) and further saturated by Guitton et al. (submitted). The final integrated map consisted of 164 genetic markers and covered $1037 \mathrm{cM}$. QTL analysis was carried out using MapQTL 4 (Van Ooijen et al. 2002) on the mean phenotypic value of all repetitions. For each variable, the logarithm of the odds (LOD) threshold value, at which a QTL was declared significant, was computed according to a genome-wide error rate of 0.05 over 1000 permutations of the data (Churchill \& Doerge 1994). An interval mapping analysis was then performed with a step size of $1 \mathrm{cM}$ in order to identify regions with potential QTL effects. QTLs were declared significant if the maximum LOD exceeded the genome-wide threshold previously calculated. Subsequently, the nearest marker to each QTL peak was selected as cofactor, and a multiple 
Table 1. Traits investigated in the 'Starkrimson' $\times$ 'Granny Smith' apple progeny at stem level (36-cm-long stem) for morphology, anatomy, and xylem hydraulic efficiency and safety, and value of these traits (mean over the whole progeny, and first and seventh octiles) with broad sense heritability $\left(h^{2}{ }_{\mathrm{b}}\right)$ and confidence interval (CI at $\left.95 \%\right)$

\begin{tabular}{|c|c|c|c|c|c|}
\hline Trait & Abbreviation & Unit & Values & $h_{\mathrm{b}}^{2}$ & CI $(95 \%)$ \\
\hline \multicolumn{6}{|l|}{ Stem morphology } \\
\hline Bottom diameter & $\mathrm{BD}$ & $\mathrm{mm}$ & $6.2(5.4-6.9)$ & 0.81 & $0.72-0.86$ \\
\hline Top diameter & TD & $\mathrm{mm}$ & $3.2(2.8-3.7)$ & 0.70 & $0.58-0.79$ \\
\hline \multicolumn{6}{|l|}{ Stem anatomy } \\
\hline Pith area & PA & $\mu \mathrm{m}^{2}$ & $\begin{array}{l}1327478.9 \\
\quad(1048032.6-1672765.4)\end{array}$ & 0.75 & $0.65-0.82$ \\
\hline Wood area & WA & $\mu \mathrm{m}^{2}$ & $\begin{array}{l}1770421.8 \\
\quad(1182581.4-2464564.8)\end{array}$ & 0.81 & $0.73-0.86$ \\
\hline $\begin{array}{l}\text { Proportion of wood area } \\
(\text { ratio WA/(WA + PA }))\end{array}$ & WAprop & & $0.56(0.46-0.66)$ & 0.81 & $0.72-0.86$ \\
\hline \multicolumn{6}{|l|}{ Wood anatomy } \\
\hline Number of xylem vessels & $\mathrm{VN}$ & & $1123.1(826.4-1468.2)$ & 0.80 & $0.71-0.85$ \\
\hline $\begin{array}{l}\text { Total area of lumen of } \\
\text { xylem vessels }\end{array}$ & VA & $\mu \mathrm{m}^{2}$ & $\begin{array}{l}209749.0 \\
\quad(129039.6-281852.1)\end{array}$ & 0.78 & $0.68-0.84$ \\
\hline $\begin{array}{l}\text { Vessel density (ratio } \\
\text { VN/WA) }\end{array}$ & VD & $\mu \mathrm{m}^{-2}$ & $\begin{array}{c}65.810^{-5}\left(55.010^{-5}-75.7\right. \\
\left.10^{-5}\right)\end{array}$ & 0.70 & $0.58-0.79$ \\
\hline $\begin{array}{l}\text { Hydraulic vessel } \\
\text { diameter }\end{array}$ & $D_{\mathrm{h}}$ & $\mu \mathrm{m}$ & $18.9(17.2-20.6)$ & 0.77 & $0.67-0.84$ \\
\hline $\begin{array}{l}\text { Proportion of vessels } \\
\text { within quartile } 1 \\
\text { (narrow vessels) }\end{array}$ & PVQ1 & & $0.27(0.20-0.35)$ & 0.68 & $0.55-0.77$ \\
\hline $\begin{array}{l}\text { Proportion of vessels } \\
\text { within quartile } 4 \text { (large } \\
\text { vessels) }\end{array}$ & PVQ4 & & $0.23(0.11-0.34)$ & 0.77 & $0.67-0.83$ \\
\hline \multicolumn{6}{|l|}{ Hydraulic efficiency } \\
\hline Hydraulic conductivity & $K_{\mathrm{h}}$ & $\mathrm{mmol} \mathrm{s}^{-1} \mathrm{MPa}^{-1} \mathrm{~m}$ & $0.26(0.14-0.35)$ & 0.77 & $0.67-0.83$ \\
\hline $\begin{array}{l}\text { Theoretical hydraulic } \\
\text { conductivity }\end{array}$ & $K_{\mathrm{ht}}$ & $\mathrm{mmol} \mathrm{s}{ }^{-1} \mathrm{MPa}^{-1} \mathrm{~m}$ & $0.12(0.06-0.17)$ & 0.73 & $0.61-0.80$ \\
\hline $\begin{array}{l}\text { Hydraulic specific } \\
\text { conductivity (ratio } \\
\left.K_{\mathrm{h}} / \mathrm{VA}\right)\end{array}$ & $K_{\mathrm{hs}}$ & $\mathrm{mmol} \mathrm{s}^{-1} \mathrm{MPa}^{-1} \mathrm{~m} \mu \mathrm{m}^{-2}$ & $\begin{array}{l}1.2310^{-6}\left(9.0810^{-7}-1.52\right. \\
\left.10^{-6}\right)\end{array}$ & 0.21 & $-0.12-0.43$ \\
\hline \multicolumn{6}{|l|}{ Hydraulic safety } \\
\hline $\begin{array}{l}\text { Tension value causing } \\
50 \% \text { loss of hydraulic } \\
\text { conductivity }\end{array}$ & $P_{50}$ & $\mathrm{MPa}$ & $-4.3(-5.2-3.3)$ & 0.79 & $0.69-0.86$ \\
\hline Slope at $P_{50}$ & SL & $\% \mathrm{MPa}$ & $23.2(17.7-29.4)$ & 0.58 & $0.37-0.71$ \\
\hline
\end{tabular}

QTL mapping (MQM, Jansen \& Stam 1994) was performed. Following the MQM mapping step, each significant QTL was characterized by its LOD score, the percentage of phenotypic variation explained and its $\mathrm{CI}$ in centiMorgan (cM), corresponding to a LOD score drop of 2 on either side of the likelihood peak. QTL location on the integrated genetic map was represented using MapChart (Voorrips 2001).

\section{RESULTS}

\section{Broad-sense heritability and correlations between anatomical and hydraulic traits}

Whatever the category to which they belonged to (stem morphology and anatomy, wood anatomy and hydraulics), the variables were generally highly heritable with $h_{\mathrm{b}}^{2}$ values between 0.58 (for slope) to 0.81 (for the three variables bottom diameter, wood area and wood area proportion)
(Table 1). There was no lower threshold of CI below 0.37 (for slope; Table 1 ). $K_{\mathrm{hs}}$ was the only exception with the lowest $h_{\mathrm{b}}^{2}$ value $(0.21)$ and a lower limit of CI negative $(-0.12$; Table 1). Phenotypic correlations and PCA were then carried out on all the variables, but $K_{\mathrm{hs}}$ across the whole progeny.

The analyses of phenotypic correlations among the variables showed the following results (Table 2). The two variables of hydraulic safety $\left(P_{50}\right.$, slope) were positively correlated to each other, but not correlated with the other variables. Among the other variables, there were generally positive correlations between the variables of stem morphology and anatomy, wood anatomy and hydraulic efficiency, meaning that an increase of bottom diameter and top diameter was related to an increase of anatomical traits (vessel number, vessel area, wood area, wood area proportion), and of $K_{\mathrm{h}}$ and $K_{\mathrm{ht}}$. There were, however, two exceptions. Firstly, pith area was positively correlated with top diameter, and negatively with wood area proportion. 
Table 2. Phenotypic correlations between variables of stem morphology and anatomy, and wood anatomy and hydraulics (see Table 1) selected on the basis of their significant broad-sense heritability value $\left(h^{2}{ }_{\mathrm{b}}\right)$ across the 'Starkrimson' $\times$ 'Granny Smith' apple progeny

\begin{tabular}{|c|c|c|c|c|c|c|c|c|c|c|c|c|c|c|c|}
\hline & $\mathrm{BD}$ & $\mathrm{TD}$ & PA & WA & WAprop & $\mathrm{VN}$ & VA & VD & $D_{\mathrm{h}}$ & PVQ1 & PVQ4 & $K_{\mathrm{h}}$ & $K_{\mathrm{ht}}$ & $P_{50}$ & SL \\
\hline \multicolumn{16}{|c|}{ Stem morphology } \\
\hline $\mathrm{BD}$ & 1.00 & & & & & & & & & & & & & & \\
\hline TD & 0.65 & 1.00 & & & & & & & & & & & & & \\
\hline \multicolumn{16}{|c|}{ Stem anatomy } \\
\hline $\mathrm{PA}$ & 0.11 & 0.54 & 1.00 & & & & & & & & & & & & \\
\hline WA & 0.70 & 0.78 & 0.15 & 1.00 & & & & & & & & & & & \\
\hline WAprop & 0.58 & 0.42 & -0.41 & 0.79 & 1.00 & & & & & & & & & & \\
\hline \multicolumn{16}{|c|}{ Wood anatomy } \\
\hline VN & 0.65 & 0.78 & 0.20 & 0.93 & 0.71 & 1.00 & & & & & & & & & \\
\hline VA & 0.64 & 0.77 & 0.21 & 0.92 & 0.69 & 0.94 & 1.00 & & & & & & & & \\
\hline VD & -0.49 & -0.50 & -0.05 & -0.67 & -0.62 & -0.39 & -0.46 & 1.00 & & & & & & & \\
\hline $\mathrm{D}_{\mathrm{h}}$ & 0.27 & 0.43 & 0.21 & 0.45 & 0.34 & 0.41 & 0.65 & -0.39 & 1.00 & & & & & & \\
\hline PVQ1 & -0.32 & -0.45 & -0.16 & -0.50 & -0.40 & -0.48 & -0.69 & 0.37 & -0.87 & 1.00 & & & & & \\
\hline PVQ4 & 0.34 & 0.47 & 0.18 & 0.51 & 0.39 & 0.47 & 0.71 & -0.41 & 0.97 & -0.92 & 1.00 & & & & \\
\hline \multicolumn{16}{|c|}{ Hydraulic efficiency } \\
\hline$K_{\mathrm{h}}$ & 0.66 & 0.67 & 0.12 & 0.82 & 0.65 & 0.81 & 0.85 & -0.46 & 0.51 & -0.56 & 0.59 & 1.00 & & & \\
\hline$K_{\mathrm{ht}}$ & 0.60 & 0.73 & 0.21 & 0.86 & 0.64 & 0.86 & 0.98 & -0.47 & 0.75 & -0.74 & 0.81 & 0.83 & 1.00 & & \\
\hline \multicolumn{16}{|c|}{ Hydraulic safety } \\
\hline$P_{50}$ & 0.01 & 0.01 & 0.15 & -0.02 & -0.11 & 0.02 & 0.04 & 0.08 & 0.09 & -0.05 & 0.08 & 0.03 & 0.05 & 1.00 & \\
\hline SL & -0.07 & -0.06 & -0.01 & -0.05 & -0.06 & -0.04 & -0.07 & 0.06 & -0.08 & 0.06 & -0.08 & -0.02 & -0.08 & 0.41 & 1.00 \\
\hline
\end{tabular}

Bold numbers indicate significant correlation coefficient $(R)$ at $P<0.01$.

Secondly, vessel density and the proportion of small vessels were positively correlated to each other (the more numerous the vessels, the narrower they are), but negatively correlated with the other variables except pith area and the two positively correlated safety variables, $P_{50}$ and slope.

Two correlations need a further comment. Firstly, although vessel number was positively correlated with both the number of narrow and large vessels (Fig. 2), the slope of the relationship was steeper with the latter than with the former, resulting in a negative correlation between vessel number and the proportion of small vessels, and a positive correlation between vessel number and the proportion of large vessels (Table 2 ). Secondly, $K_{\mathrm{ht}}$ was positively and linearly correlated with $K_{\mathrm{h}}$ (Table 2 ). However, $K_{\mathrm{ht}}$ underestimated $K_{\mathrm{h}}$ by a factor of proportionality of c. 2.35 (data not shown).

The clustering analysis revealed six groups (Fig. 3). Four clusters were composed of isolated variables: two clusters were related to anatomical variables (pith area, vessel density), and two clusters were related to hydraulic safety (slope, $P_{50}$ ). The two other clusters, termed synthetic clusters, were composed of several variables. The first cluster, termed groupD for diameter, included the three variables related to vessel diameter, proportion of small vessels, proportion of large vessels and $D_{\mathrm{h}}$. The second cluster, termed groupC for conductivity, included hydraulic conductivity $\left(K_{\mathrm{ht}}, K_{\mathrm{h}}\right)$ and all the correlated variables: bottom diameter, top diameter, vessel number, vessel area, wood area, wood area proportion. The first component of the PCA carried out on each synthetic cluster, groupD and groupC, took into account 95 and $79 \%$ of variance, respectively. Within groupD, the proportion of large vessels was the most correlated to the first principal component of the PCA carried out on the cluster $(R=0.99)$. Within groupC, vessel area and wood area contributed equally to the first principal component of the PCA carried out on the cluster $(R=0.97)$ (Table 3).

The PCA carried out on the new set of variables [i.e. the single ones and the two new synthetic variables (groupD

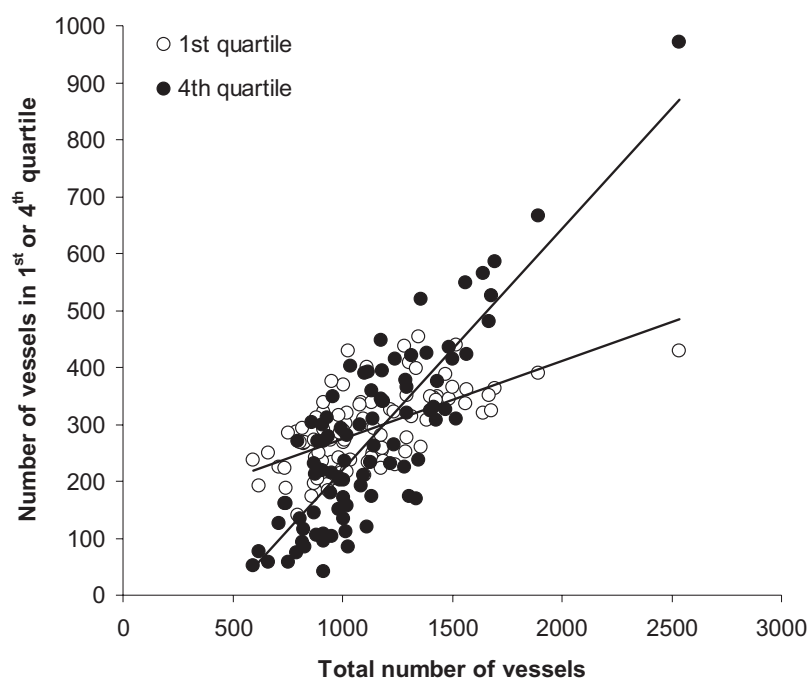

Figure 2. Relationship between the total number of vessels $(\mathrm{VN})$, and the number of vessels in the first and the fourth quartiles of vessel cross-section area, corresponding to 'narrow' and 'large' vessels, respectively (see text) over the 90 apple genotypes of the 'Starkrimson' $\times$ 'Granny Smith' progeny. Equation line formula: number of vessels in the first quartile: $y=0.137 x+137.37\left(R^{2}=0.379 ; P<0.01\right)$; number of vessels in the fourth quartile: $y=0.424 x-203.24\left(R^{2}=0.708 ; P<0.01\right)$. 


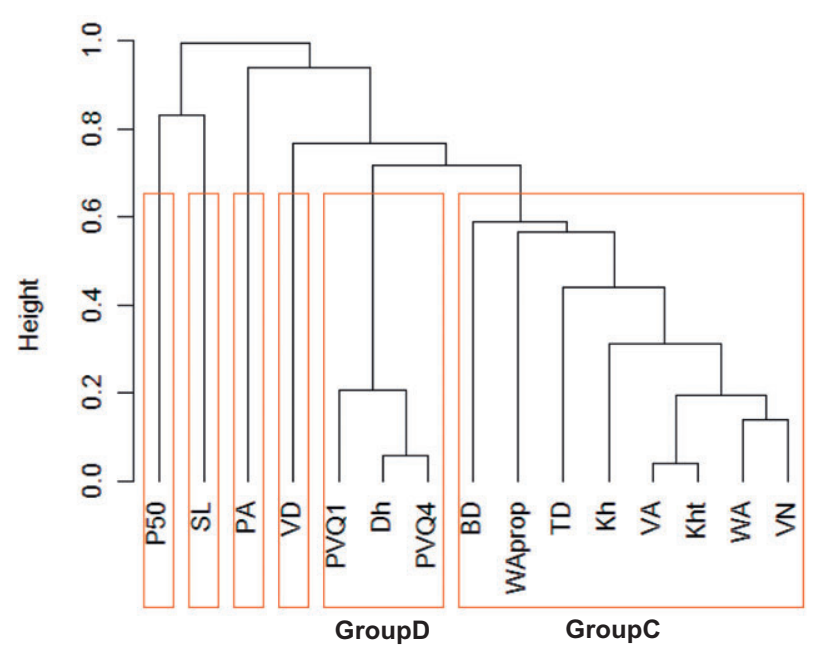

Figure 3. Cluster dendrogram based on the $\operatorname{sine}^{2}$ distance matrix between the variables investigated in the 'Starkrimson' $\times$ 'Granny Smith' apple progeny at stem level for morphology, anatomy, and xylem hydraulic efficiency and safety (agglomeration method 'average'). Four clusters were composed each of a single variable, $P_{50}$, slope, pith area and vessel density. Two clusters, groupD and groupC, were synthetic clusters including three variables related to vessel diameter (proportion of small vessels, proportion of large vessels, $D_{\mathrm{h}}$ ) and eight variables related to hydraulic conductivity (bottom diameter, top diameter, vessel number, vessel area, wood area, wood area proportion, $K_{\mathrm{ht}}, K_{\mathrm{h}}$ ), respectively.

and groupC) represented by their first PC] showed that $75.4 \%$ of the total variance was taken into account by the first three PCs (35.3, 24.1 and $16.1 \%$ of the whole variance, respectively; Fig. 4). PC1 was mainly explained by hydraulic efficiency variables at both anatomical (groupD) and hydraulic (groupC) levels, which were negatively correlated with vessel density. PC2 was mainly explained by hydraulic safety variables $\left(P_{50}\right.$ and slope). PC3 was mainly explained by the single variable pith area (Table 4). Although there was a large distribution of genotypes within the space of PC1-PC2 (Fig. 4; PC1 versus PC2), only two genotypes ('106', '41') belonged to both the upper quartile of PC1, meaning high efficiency, and to the lower quartile of PC2, meaning high safety.

\section{QTL detection for anatomical and hydraulic traits}

QTLs were detected for all heritable traits except the $P_{50}$ variable. In the following paragraph, description of the QTLs will be divided in three groups of variables depending on QTL co-localizations.

In the first group of variables, which includes wood area, vessel number, wood area proportion, vessel area, bottom diameter, top diameter, $K_{\mathrm{h}}$ and $K_{\mathrm{ht}}$, one major QTL was detected on LG08 and explained between 17.9 and 22.9\% of the variability (Table 5; Fig. 5). For vessel number and $K_{\mathrm{h}}$, the QTL was characterized mainly by a female additive effect. For the variables wood area proportion, vessel area and $K_{\mathrm{ht}}$, the QTL was characterized by both a female and a male additive effect. Finally, for wood area, bottom diameter and top diameter, the LG08 QTL displayed both a female and dominance effect.

The second group of variables included proportion of small vessels, proportion of large vessels and $D_{\mathrm{h}}$. All three variables were characterized by the identification of QTLs on LG08 and LG11. One additional QTL was also identified for $D_{\mathrm{h}}$ and was located on LG13. For proportion of small vessels, the QTL detected on LG08 explained 13.3\% of the variability, and was characterized by both a female and dominance effect. The QTL identified on LG11 explained $12 \%$ of the variability and was mostly characterized by a female additive effect. The global model estimation showed significant effect for both QTLs, with no interaction between them, and explained $19.1 \%$ of the variability. For the variable proportion of large vessels, the QTL identified on LG08 and LG11 explained 16.2 and $11.3 \%$ of the variability, respectively. Both QTLs were characterized by a female and a dominance effect. The global model built for these two QTLs confirmed the significance of the markers, which together explained $18.9 \%$ of the trait variability. Finally, the three QTLs identified for $D_{\mathrm{h}}$ on LG08, LG11 and LG13 explained 20.1,11.2 and 9.7\% of the variability, respectively. QTLs identified on LG08 and LG13 displayed a strong male additive effect, while the QTL located on LG11 resulted from a female additive effect. The global model built for this variable explained $33.2 \%$ of the variability.

The last group is composed by the variables slope, pith area and vessel density. QTLs detected for these variables did not co-locate with any of the genomic regions previously identified, and among each other. One QTL located on LG02 and explaining $30.4 \%$ of the variability was identified for the variable slope. This QTL was characterized by a dominance effect. For the variable pith area, one QTL was also detected on LG02, but was located in a different zone than the one for slope. This QTL explained $23.2 \%$ of the

Table 3. Correlations between original variables measured on the 'Starkrimson' $\times$ 'Granny Smith' apple progeny and the first principal component of the principal component analysis (PCA) carried out within each group of clustered variables (i.e. the two synthetic variables groupD and groupC)

\begin{tabular}{lcl}
\hline & GroupD & GroupC \\
\hline$D_{\mathrm{h}}$ & 0.97 & - \\
PVQ1 & -0.95 & - \\
PVQ4 & 0.99 & - \\
$K_{\mathrm{h}}$ & - & 0.89 \\
$K_{\mathrm{ht}}$ & - & 0.93 \\
$\mathrm{BD}$ & - & 0.77 \\
$\mathrm{TD}$ & - & 0.82 \\
VN & - & 0.95 \\
VA & - & 0.97 \\
WA & - & 0.97 \\
WAprop & - & 0.77 \\
\hline
\end{tabular}



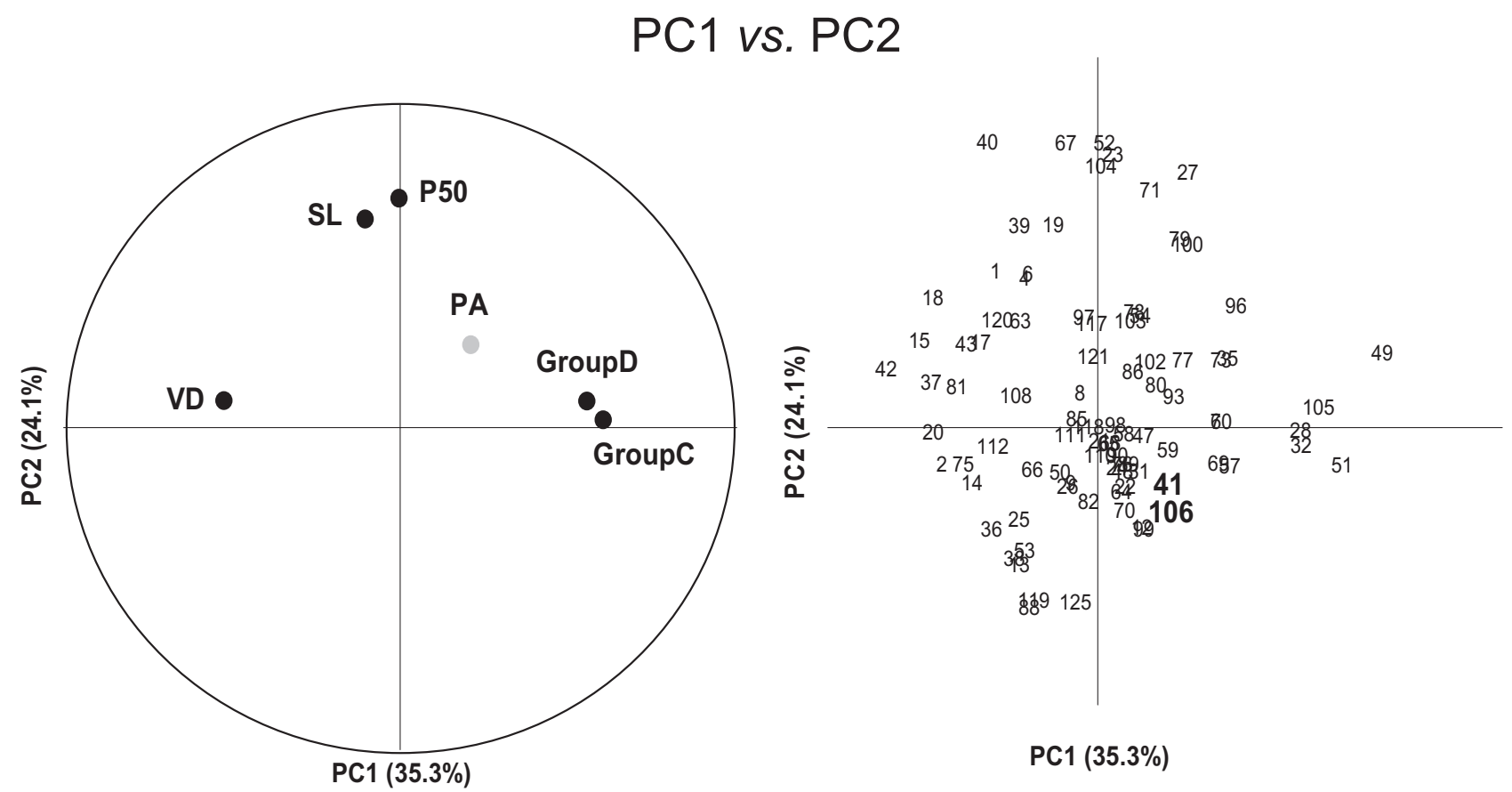

PC2 vs. PC3
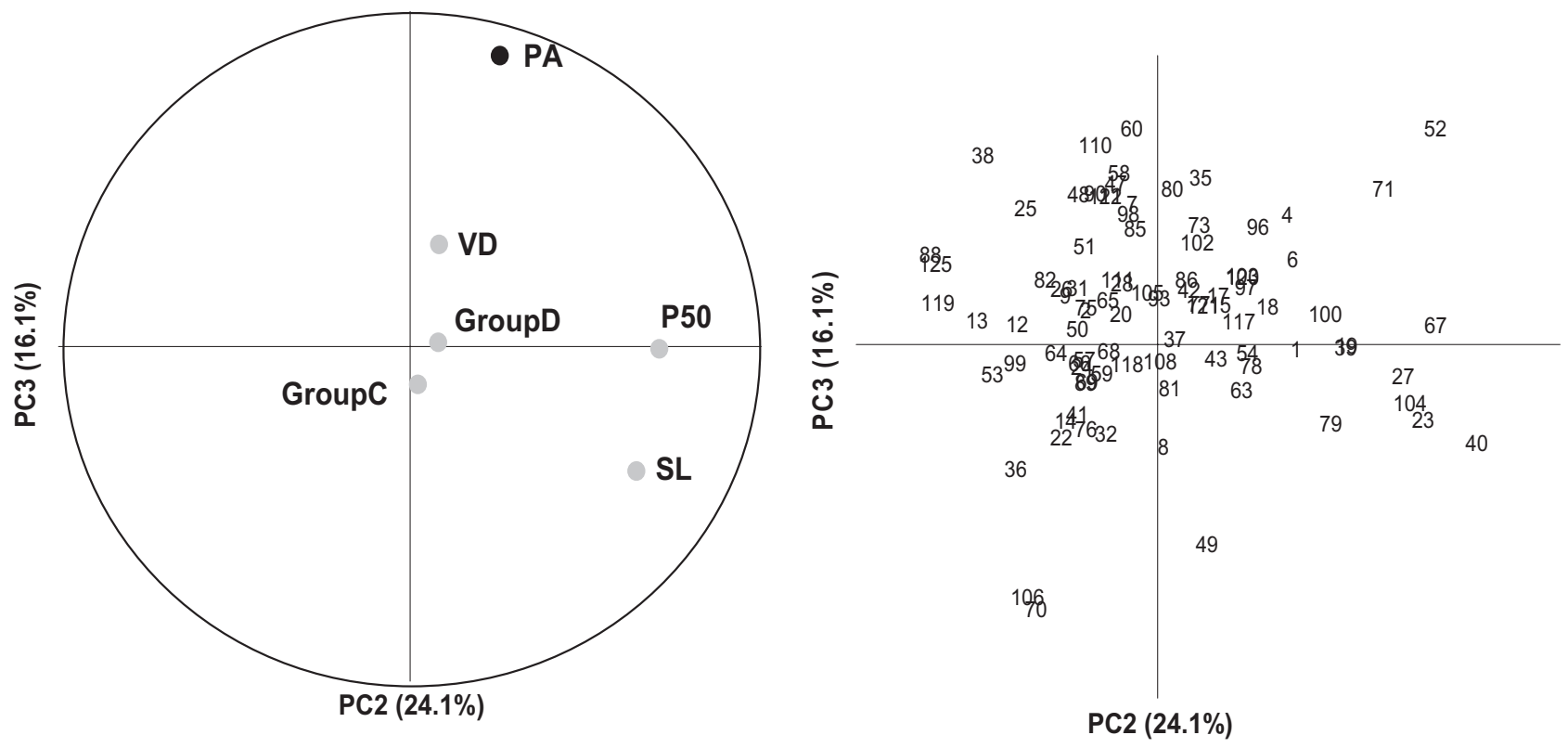

Figure 4. Scattergram of principal components 1 (PC1) and 2 (PC2), and 2 (PC2) and 3 (PC3), with projections of the variables (left) and genotypes (right) for variables investigated in the 'Starkrimson' $\times$ 'Granny Smith' apple progeny. On PC1 axis, efficiency (high conductivity and correlated variables) increases from left to right. On PC2 axis, safety (high absolute values of $P_{50}$ ) increases from top to bottom. On PC3 axis, pith area increases from bottom to top. In projection of the variables, black and grey symbols indicate variables with a high versus a low link with PC1 and PC2 in 'PC1 versus PC2' graph, and with PC3 in 'PC2 versus PC3' graph, respectively (see Table 4). In projection of the genotypes, large bold numbers are for the two genotypes ('41', '106') with values in the highest (high efficiency on PC1) and lowest (high safety on PC2) quartiles of all genotypes. GroupD includes the variables: proportion of small vessels, proportion of large vessels and $D_{\mathrm{h}}$. GroupC includes the variables: bottom diameter, top diameter, vessel number, vessel area, wood area, wood area proportion, $K_{\mathrm{ht}}$ and $K_{\mathrm{h}}$. 
Table 4. Loadings of the variables measured on the 'Starkrimson' $\times$ 'Granny Smith' apple progeny, $P_{50}$, slope (SL), pith area (PA), vessel density (VD), and clusters of variables groupD (proportion of small vessels, proportion of large vessels, $D_{\mathrm{h}}$ ) and groupC (bottom diameter, top diameter, vessel number, vessel area, wood area, wood area proportion, $K_{\mathrm{ht}}, K_{\mathrm{h}}$ ), on the three principal components, $\mathrm{PC} 1, \mathrm{PC} 2$ and $\mathrm{PC} 3$ of the principal component analysis (PCA) in Fig. 4

\begin{tabular}{lrrr}
\hline & \multicolumn{1}{c}{ PC1 } & PC2 & \multicolumn{1}{c}{ PC3 } \\
\hline$P_{50}$ & -0.003 & $\mathbf{0 . 7 1 0}$ & -0.008 \\
SL & -0.104 & $\mathbf{0 . 6 4 5}$ & -0.373 \\
PA & 0.210 & 0.256 & $\mathbf{0 . 8 6 8}$ \\
VD & $\mathbf{- 0 . 5 2 3}$ & 0.083 & 0.304 \\
GroupD & $\mathbf{0 . 5 5 5}$ & 0.081 & 0.012 \\
GroupC & $\mathbf{0 . 6 0 3}$ & 0.023 & -0.114 \\
\hline
\end{tabular}

For a given principal component, value(s) in bold indicate(s) variable(s) or cluster(s) of variables defining mainly this principal component.

variability and was characterized by a dominance effect. Finally, one QTL explaining $22.8 \%$ of the variability and characterized by a dominance effect was detected on LG09 for the variable vessel density.

\section{DISCUSSION}

\section{Interests and limits of the present study}

Our study aimed at analyzing how several variables characterizing stem morphology, stem and wood anatomy, and stem xylem efficiency and safety were segregating within an apple progeny. The focus was on the correlations between these sets of variables with an insight on their genetic determinism through a QTL analysis. Although the ecological and agronomic interest of hydraulic studies is repeatedly pinpointed (Cochard et al. 2008), this challenging issue is poorly documented on horticultural perennials. Combining these various approaches was tedious and time consuming, especially for measuring VCs even though the Cochard cavitron is recognized as one of the fastest method (Cai et al. 2010). In the two alternatives of our Cornelian dilemma (i.e. whether increasing the number of genotypes to the detriment of the number of repetitions or the reverse), our objective was to get an insight into the variability of trait values across as many genotypes as possible with only a single tree per genotype. The studied variables also imposed sampling constraints related to the technique used. This was the case here for the study of cavitation for which the use of the Cavitron spinning technique imposed a minimum length of stem (Cochard et al. 2010). Based on preliminary studies (Cochard, unpublished results) the choice was made to work on 36-cm-long stems. The same stem length was then applied to the hydraulic conductivity analyses (HPFM). There is new evidence that stem length changes the VCs, as well as hydraulic conductivity as measured with both centrifugation and air injection techniques (Cruiziat et al. 2002; Choat et al. 2010; Cochard et al. 2010; Ennajeh et al. 2011). Our further comments will then be restricted to this stem-length category bearing in mind that, in certain cases this may not be representative of the genotype

Table 5. Parameters associated with quantitative trait loci (QTLs) detected by multiple QTL mapping (MQM) for the stem morphological and wood anatomical, and xylem hydraulic variables measured on the 'Starkrimson' × 'Granny Smith' apple progeny

\begin{tabular}{|c|c|c|c|c|c|c|c|c|c|c|c|}
\hline Trait & LG & Position (cM) & Locus & LOD & LOD max & $\mathrm{LM} p$ & $R^{2}$ & Global $R^{2}$ & $A_{\mathrm{m}}$ & $A_{\mathrm{f}}$ & $D$ \\
\hline WA & 8 & 35.2 & MdPI & 4.61 & 4.68 & & 0.224 & & $-5.710^{-5}$ & $7.510^{-5}$ & $-7.310^{-5}$ \\
\hline $\mathrm{VN}$ & 8 & 35.2 & MdPI & 4.01 & & & 0.193 & & -271.98 & 318.96 & -268.12 \\
\hline Waprop & 8 & 35.2 & MdPI & 3.56 & 3.69 & & 0.183 & & -0.077 & 0.078 & -0.057 \\
\hline VA & 8 & 35.2 & MdPI & 4.53 & & & 0.216 & & -84027 & 89351 & -53141 \\
\hline $\mathrm{BD}$ & 8 & 35.2 & MdPI & 3.61 & & & 0.189 & & -0.287 & 0.798 & -0.893 \\
\hline TD & 8 & 35.2 & MdPI & 2.74 & & & 0.185 & & -0.176 & 0.298 & -0.326 \\
\hline$K_{\mathrm{h}}$ & 8 & 35.2 & MdPI & 3.12 & 3.16 & & 0.179 & & -0.071 & 0.137 & -0.061 \\
\hline$K_{\mathrm{ht}}$ & 8 & 35.2 & MdPI & 4.54 & & & 0.229 & & -0.063 & 0.067 & -0.032 \\
\hline \multirow[t]{2}{*}{ PVQ1 } & 11 & 0 & ch04h02 & 2.99 & & $* *$ & 0.120 & 0.191 & 3.436 & 6.968 & 4.481 \\
\hline & 8 & 19.4 & Hi04b12 & 2.91 & & $*$ & 0.133 & & 3.330 & -4.907 & 5.780 \\
\hline \multirow[t]{2}{*}{ PVQ4 } & 11 & 0 & ch04h02 & 2.78 & & $* *$ & 0.113 & 0.189 & -4.036 & -10.554 & -6.860 \\
\hline & 8 & 19.4 & Hi04b12 & 3.15 & 3.38 & $*$ & 0.162 & & -6.549 & 8.474 & -8.047 \\
\hline \multirow[t]{3}{*}{$D_{\mathrm{h}}$} & 8 & 35.2 & MdPI & 5.6 & & $* * *$ & 0.201 & 0.332 & -2.221 & 0.953 & -0.038 \\
\hline & 11 & 0 & $\operatorname{ch} 04 \mathrm{~h} 02$ & 3.25 & & $* *$ & 0.112 & & -0.807 & -1.521 & -0.985 \\
\hline & 13 & 20.3 & $\operatorname{ch} 02 \mathrm{~g} 01$ & 3.05 & & $* *$ & 0.097 & & 1.841 & -0.446 & -1.242 \\
\hline SL & 2 & 71 & $\operatorname{ch} 03 \mathrm{~d} 01$ & 3.51 & 3.58 & $*$ & 0.304 & & 4.937 & -0.233 & -9.695 \\
\hline $\mathrm{PA}$ & 2 & 49.9 & $\operatorname{ch} 02 \mathrm{c} 06$ & 4.29 & & & 0.232 & & $1.810^{-5}$ & $-2.910^{-5}$ & $4.410^{-5}$ \\
\hline VD & 9 & 0 & NH029 & 3.6 & & & 0.228 & & $-8.910^{-6}$ & $6.310^{-5}$ & $1.510^{-4}$ \\
\hline$P_{50}$ & NoQTL & & & & & & & & & & \\
\hline
\end{tabular}

For each trait is described, the linkage group (LG) where the QTL was identified, position on the map, name of the closest locus to the logarithm of the odds (LOD) pick, LOD value, significance of the marker used in the construction of the linear model (LM $p$ ), variability explained by the QTL $\left(R^{2}\right)$, global variability explained by all the QTLs detected for one trait (global $\left.R^{2}\right)$, male $\left(A_{\mathrm{m}}\right)$ and female $\left(A_{\mathrm{f}}\right)$ additive effects, and dominance $(D)$ effects.

$* P<0.05 ; * P<0.01 ; * * * P<0.001$. 


\section{LG02}

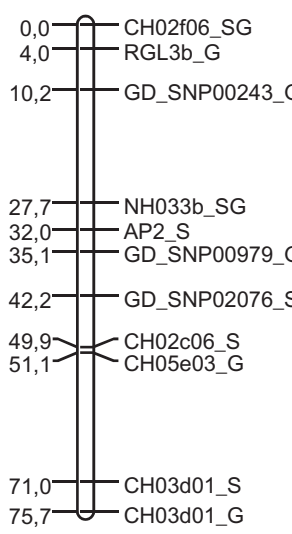

LG08

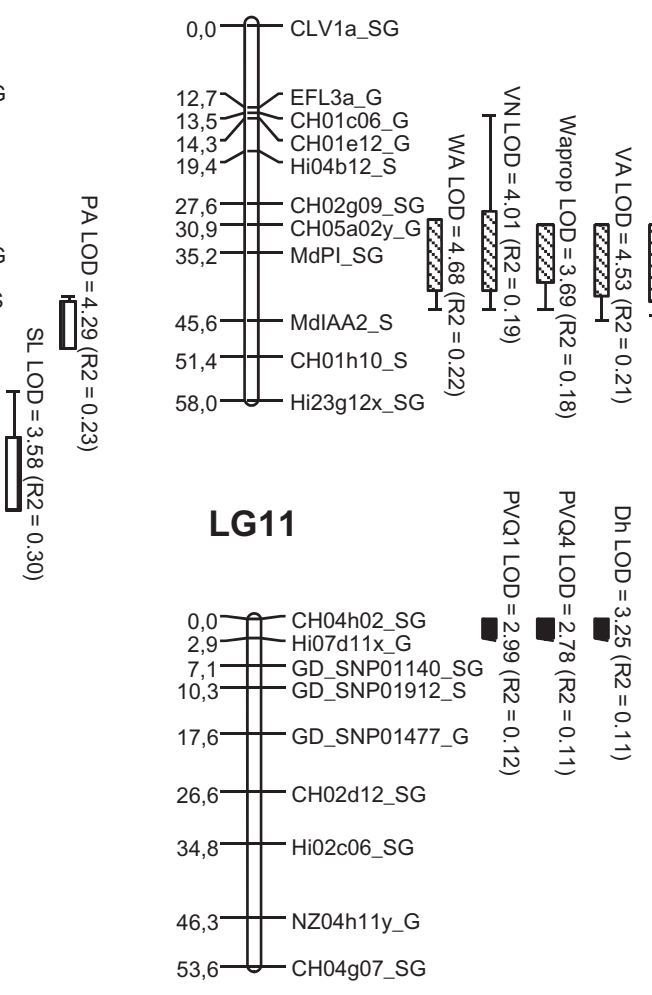

LG09

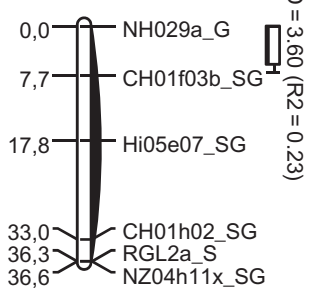

LG13

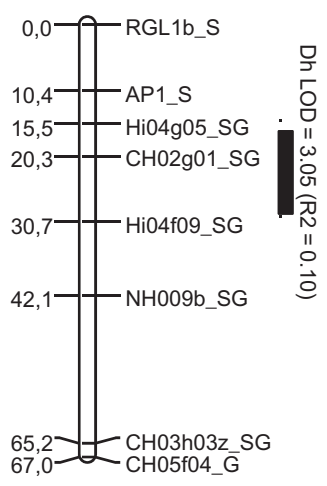

Figure 5. Genomic position of quantitative trait loci (QTLs) detected on the linkage groups of the integrated 'Starkrimson' $\times$ 'Granny Smith' map by multiple QTL mapping (MQM). QTLs are represented by boxes extended by lines representing the logarithm of the odds (LOD)-1 and LOD-2 confidence intervals (CIs). Variables from groupC (bottom diameter, wood area proportion, top diameter, $K_{\mathrm{h}}, K_{\mathrm{ht}}$, vessel area, wood area, vessel number) are in hashed boxes, variables from groupD (proportion of small vessels, proportion of large vessels, $D_{\mathrm{h}}$ ) are in black boxes and other independant variables (slope, pith area and vessel density) are in white boxes. Numbering of the linkage groups (LG) is according to Maliepaard et al. (1998).

architecture, especially for genotypes with a high frequency of short shoots (Segura et al. 2006).

\section{Variability of hydraulic efficiency and anatomical traits}

The broad sense heritability values of almost all investigated traits obtained in our apple progeny (0.58-0.81; Table 1) were above the range of heritabilities generally encountered in natural populations (i.e. 0.2-0.5) (Walsh 2001), and to values obtained for architectural and morphological traits on the same progeny $(0.55-0.68$ with lower limits of CIs from 0.36-0.54; Segura et al. 2007). In a previous study on Norway spruce clones, Rosner et al. (2007) pointed the low heritability of hydraulic safety traits. Although, in our case, the heritability values were likely biased upward because of the use of a single tree per genotype and a single environment (Scully, Wallace \& Viands 1991), the high values we obtained are worth noticing and would surely need confirmation integrating experiments on several trees per genotype and ideally various environments.
The apple wood is diffuse porous composed of homogeneous narrow vessels (Pratt 1990) having a more progressive embolism compared to ring-porous species with large vessels and characterized by drastic increase in embolism, especially freezing-induced cavitation (Cochard 2006). We were not able to classify the apple genotypes in one of the diffuse-porous wood types (d1, d2) defined by Umebayashi et al. (2010), because the water-conducting patterns in early and late wood were not considered in our study. However, the mean value of the hydraulic diameter $\left(D_{\mathrm{h}}\right)$ we found (i.e. $18.9 \mu \mathrm{m}$ ) was quite similar to the lower limit shown by these authors on a range of diffuse-porous wood broadleaved species. Similarly, the mean value of hydraulic conductivity $\left(K_{\mathrm{h}}\right)$ (i.e. $0.26 \mathrm{mmol} \mathrm{s}^{-1} \mathrm{MPa}^{-1} \mathrm{~m}$ ) was similar, after unit transformation, to the mean value for currentyear long shoots of the deciduous broadleaved species Fagus sylvestris (Cruiziat et al. 2002). When $K_{\mathrm{h}}$ was expressed as a ratio to total vessel area [i.e. hydraulic specific conductivity $\left(K_{\mathrm{hs}}\right)$ ], it did not vary consistently across the apple genotypes studied here, falling in the range of values established by Tyree \& Zimmermann (2002) for angiosperms. The fact that $K_{\mathrm{hs}}$ had a low heritability, and 
that it did not take into account the variability of vessel size highly related to vessel conductivity (see below) would question the interest of this variable to discriminate between genotypes, at least at the intra-species level with same wood characteristics.

The mean value of $P_{50}$ (i.e. $-4.3 \mathrm{MPa}$ ) (Table 1 ) was between the ranges observed in two extreme genus, the highly resilient Callitris trees ( -9 to -15 ; Brodribb et al. 2010) and the highly vulnerable to drought-induced cavitation Populus ( -1.60 to $-2.40 \mathrm{MPa}$; Fichot et al. 2010). Our results were similar to the values obtained on Prunus species by Cochard et al. 2008 ( -3.5 to -6.5$)$, and also on various species belonging to the drought deciduous shrubs group by Maherali et al. (2004). On the other hand, the mean value of the slope of the VC (i.e. $23.2 \% \mathrm{MPa}$ ) (Table 1) was well under the range of values found by Cochard et al. (2008) on the Prunus species (i.e. c. $35-105 \%$ $\mathrm{MPa})$, meaning that the progression of embolism within the stem was much lower in our apple progeny compared to the studied Prunus species. All together, the $P_{50}$ and slope values obtained across the whole apple progeny are in accordance with the known ability of the apple tree among other fruit tree species to adapt to various environments, especially dry conditions (Webster 2005).

\section{Phenotypic correlations between traits}

The phenotypic correlations between traits clearly highlighted the major positive contribution of the proportion of large vessels to $D_{\mathrm{h}}$, and to $K_{\mathrm{h}}$ and $K_{\mathrm{ht}}$ (Table 3), confirming previous works (Tyree \& Sperry 1989; Steppe \& Lemeur 2007; Russo et al. 2010). Although not investigated here, it is likely that vessel diameter per se can be used as a proxy for the whole tree growth potential (Tombesi et al. 2010). Our study clearly showed that genotypes with large wood area, and to a lesser extent large-diameter stems (bottom diameter, top diameter), not only had more vessels (positive correlation with vessel number), but also had a higher proportion of large vessels to the detriment of narrow ones (negative correlation with the proportion of small vessels). Whether these patterns of wood areavessel area relationships are related to a genotypedependent secondary growth duration remains to be further documented. The inverse relationship between vessel area and vessel density shown here at the intraspecies level (vessel density positively correlated with the proportion of small vessels and negatively with the proportion of large vessels) was also found on a range of woody species belonging to several families, genera and species (Russo et al. 2010). Although not investigated here, it is likely that this trade-off between hydraulic efficiency and vessel density is correlated to mechanical stability of the xylem (Sellin et al. 2008). Eventually, the good correlation of the highly heritable wood area with all other more arduous to measure efficiency traits strongly supports the interest of wood area as the easiest-to-measure trait, among all traits considered here, to estimate water transport efficiency of a genotype.
The theoretical hydraulic conductivity $\left(K_{\mathrm{ht}}\right)$ calculated from Poiseuille equation for ideal capillaries of circle stem cross-section underestimated the hydraulic conductivity $\left(K_{\mathrm{h}}\right)$ measured with the HPFM apparatus by a factor of 2.35 (data not shown). As documented (e.g. Tyree \& Zimmermann 2002), measured conductivity is generally lower than theoretical conductivity, which is contrary to what we observed here. In our results, a unique ratio accounted for differences between the two variables across all genotypes, suggesting that the same bias analysis was applied to all slides leading to a proportional increase of measuring error with $K_{\mathrm{h}}$ increase (i.e. with vessel area increase). This may be explained in two not excluding ways. It would first pinpoint the fact that the calculation of theoretical hydraulic conductivity does not include resistivity caused by pits which in certain cases may strongly decrease actual xylem conductivity. Secondly, it questions the methodology used in our study as routine thresholding for counting and measuring vessel lumens, for both colour (eliminating light and dark blue pixels) and area (with the choice of a minimal threshold of 10 pixel $^{2}$, i.e. $21.5 \mu \mathrm{m}^{2}$ ). This eliminated not only the narrowest vessels (less than $21.5 \mu \mathrm{m}^{2}$ ), but also decreased the area of all the vessels eliminating pixels near the cell wall (light blue).

\section{Hydraulic safety versus efficiency and anatomical traits}

The PCA analysis clearly discriminated anatomical and hydraulic traits related to xylem hydraulic efficiency (PC1) from safety hydraulic traits (PC2) (Fig. 4). As a whole, these two non-correlated axes confirmed previous works showing that macroscopic anatomical traits, such as vessel diameter or vessel density, were not involved in hydraulic safety (Tyree \& Zimmermann 2002). More precisely, as concerns the safety axis, the fact that the slope of the VC was positively correlated with $P_{50}$ illustrated that the faster the progression of embolism (steep slope), the lower the tension (in negative values) to induce cavitation. In other words, genotypes with high vulnerability to cavitation also had a fast spreading of embolism. This result confirms previous trends on stems of Prunus (Cochard et al. 2008), and more recent results on stems of various conifer species (Delzon et al.2010) and on individual vessels of Populus tremuloides (Cai \& Tyree 2010).

Principal component 3 (PC3) was composed of pith area only, indicating that this variable was poorly correlated to all other variables (Fig. 4). The negative correlation with the proportion of wood area among wood and pith area on the one hand, and the positive correlation with top stem diameter without any correlation with bottom stem diameter on the other hand (Table 2), would agree with the hypothesis of a rather constant pith area along the annual stem. Indeed, as shown by Marcelis-van Acker (1994) on rose shoots, there is a positive relationship between pith diameter and stem diameter during the first 3 weeks after the beginning of shoot development, with no more pith area increment thereafter. This is related to the fact that pith is 
formed in the sub-apical region of the stem with almost no cell division later on (Marcelis-van Acker 1994; Ripetti et al. 2008). This growth pattern results in a progressive decoupling of pith and wood area increments from the top of the stem downwards. Apart from the known water-storing role of pith (Rosell \& Olson 2007), it is likely that this phenomenon parallels the contribution of pith to stem mechanical properties. Indeed, pith has a significant mechanical contribution [i.e. modulus of elasticity (MOE) and modulus of rupture (MOR)] on the young stem and almost no contribution on the old stem (Lundström et al. 2007). A consequence of our results is that although pith constitutes a reliable marker for primary growth of trees, especially indicating the limits between consecutive annual shoots (Longuetaud \& Caraglio 2009), its interest as a morphological marker of stem girth and any variable related to hydraulic efficiency and safety does not hold true.

As well documented for annuals, the genetic improvement of yield should be conceived together with the improvement of growth conditions and plant management (Maherali et al. 2008; Kirkegaard \& Hunt 2010). Applied to the apple, a main aspect of the hydraulic balance of the tree depends on the characteristics of, and the relationships between, the two genetic parts that usually compose the tree. Indeed, the cultivated apple tree is a composite entity consisting of a scion variety selected for fruit quality grafted upon a rootstock variety selected for its aptitude to control tree size and also for its adaptation to soil abiotic (e.g. drought) and biotic (e.g. telluric pathogens and pests) conditions. How the intrinsic anatomical and hydraulic characteristics of a genotype, such as the ones analysed in the present study, interact with those of another genotype, the rootstock, needs further studies, including the specific aspect of the impact of the graft union on plant hydraulics which has already been well documented (e.g. Solari, Johnson \& Dejong 2006a,b; Vanderklein et al. 2007).

\section{Quantitative trait co-localization}

Results from the QTL analysis in the 'Starkrimson' $\times$ 'Granny Smith' population were in concordance with clustering and PCA. We have shown that variables displaying strong phenotypic correlation might also be regulated by similar genetic determinants confirming previous statements by Chen \& Hübberstedt (2010). The only exception was $P_{50}$. Although slope and $P_{50}$ were positively correlated, no QTL was detected for the latter one, whereas there was one detected for the former. This non-identification of common major QTLs between the two correlated variables might be caused by the low number of progenies used for the QTL analysis. Thus, minor and moderate common QTLs might still be present within the genome which could constitute other sources of genetic variation to be explored.

The middle section of LG08 had already been identified as controlling a wide range of traits in the 'Starkrimson' × 'Granny Smith' population studied here. QTLs were identified in this region for the biennial-bearing index, total number of inflorescence, fruit cumulative yield
(Guitton et al., submitted), some leaf ecophysiological traits such as transpiration rates and stomatal conductance (Regnard et al. 2009), as well as phenological traits such as the date of flowering and budbreak (Celton et al., submitted). Co-localization of QTLs for these variables could be explained by an increased capacity of the plant to transport water, carbohydrates and sugar to the growing organs. Thus, variables, such as fruit yield and resistance to water stress, are likely to interact with the xylem hydraulic performance in terms of both efficiency and safety.

The similar QTL location identified for the various variables might be explained by a pleiotropic QTL, or by clustering of functionally related genes (Cai \& Morishima 2002). In maize, it has been shown that QTLs and genes for growth or development are distributed non-randomly in gene clusters along the chromosomes (Khavkin \& Coe 1997). Gene clustering has already been reported in apple for various traits such as resistance to pathogens $(\mathrm{Xu} \&$ Korban 2002; Baldi et al. 2004) and allergens (Gao et al. 2005). However, considering our limited population size, we cannot discriminate between linked QTL and a pleiotropic QTL.

The final conclusion of this study is that based on the anatomical and hydraulic variables we considered here, there were no phenotypic correlations between hydraulic efficiency and hydraulic safety. This result was confirmed by the absence of common genomic regions for these two groups of variables. These findings extend to the intraspecific level: more precisely within a single progeny of 90 apple genotypes, there is no trade-off between the two groups of variables. This is consistent with the air-seeding hypothesis, not explored here, as a main mechanism of cavitation (Wheeler et al. 2005; Choat et al.2008). In a breeding perspective, the absence of correlation, at least linear, between safety and hydraulic efficiency traits (i.e. each group of traits belonging to a distinct principal component in the PCA) and the distinct QTLs detected for each group of traits suggest that it might be possible to find recombinants that would combine both characteristics. Indeed, a specificity of horticultural plants is that they have to optimally combine xylem hydraulic efficiency to ensure sufficient vegetative growth to support regular fruit production, and xylem safety - including embolism reversal as discussed by Koch \& Sillett (2009) in the context of hydraulic failure in tall trees - to ensure water transport from roots to leaves avoiding as much as possible deleterious effects of drought periods. Only two genotypes out of 90 were able to combine both an efficient and a safe xylem vascular system ('41' and '106'; Fig. 4 PC1 versus PC2). Selecting new genotypes combining safety and hydraulic efficiency will thus require further screening of crossed materials with wider genetic backgrounds of the parents and larger population sizes. Although our results on individual stems have to be confirmed at the whole-tree level, they raise the question of the underlying mechanisms of anatomical and hydraulic traits at genetic, physiological and morphological levels. Eventually, xylem safety is only one aspect of plant adaptation to drought. The coupling between xylem characteristics as 
investigated here and leaf traits, such as stomatal conductance (Cruiziat et al. 2002; Fichot et al. 2010), should be the next step to furthering the characterization of the global performance of these apple genotypes in drought-prone environments, especially if one wants to consider the isohydric versus anisohydric or near-isohydric behaviour of the genotypes (Jones 2007; Chaves et al. 2010).

\section{ACKNOWLEDGMENTS}

We thank Gilbert Garcia and Stéphane Feral for taking care of the trees in the field, André Clément-Demange for helpful discussions on heritability and two anonymous reviewers for helpful comments on the first version of the manuscript.

\section{REFERENCES}

Atkinson C.J., Else M.A., Taylor L. \& Dover C.J. (2003) Root and stem hydraulic conductivity as determinants of growth potential in grafted trees of apple (Malus pumila Mill.). Journal of Experimental Botany 54, 1221-1229.

Baldi P., Patocchi A., Zini E., Toller C., Velasco R. \& Komjanc M. (2004) Cloning and linkage mapping of resistance gene homologues in apple. Theory of Applied Genetics 109, 231-239.

Blackman C.J., Brodribb T.J. \& Jordan G.J. (2010) Leaf hydraulic vulnerability is related to conduit dimensions and drought resistance across a diverse range of woody angiosperms. New Phytologist 188, 1113-1123.

Brodribb T.J., Bowman D.J.M., Nichols S., Delzon S. \& Burlett R. (2010) Xylem function and growth rate interact to determine recovery rates after exposure to extreme water deficit. New Phytologist 188, 533-542.

Cai H.W. \& Morishima H. (2002) QTL clusters reflect character associations in wild and cultivated rice. Theory of Applied Genetics 104, 1217-1228.

Cai J. \& Tyree M.T. (2010) The impact of vessel size on vulnerability curves: data and models for within-species variability in saplings of aspen, Populus tremuloides Michx. Plant, Cell \& Environment 33, 1059-1069.

Cai J., Hacke U., Zhanga S. \& Tyree M.T. (2010) What happens when stems are embolized in a centrifuge? Testing the cavitron theory. Physiologia Plantarum 140, 311-320.

Calenge F. \& Durel C.E. (2006) Both stable and unstable QTLs for resistance to powdery mildew are detected in apple after four years of field assessments. Molecular Breeding 17, 329-339.

Chaves M.M., Zarrouk O., Francisco R., Costa J.M., Santos T., Regalado A.P., Rodrigues M.L. \& Lopes C.M. (2010) Grapevine under deficit irrigation: hints from physiological and molecular data. Annals of Botany 105, 661-676.

Chen J.W., Zhang Q., Li X.S. \& Cao K.F. (2009) Independence of stem and leaf hydraulic traits in six Euphorbiaceae tree species with contrasting leaf phenology. Planta 230, 459-468.

Chen Y. \& Hübberstedt T. (2010) Molecular basis of trait correlations. Trends in Plant Science 15, 454-461.

Choat B., Cobb A.R. \& Jansen S. (2008) Structure and function of bordered pits: new discoveries and impacts on whole-plant hydraulic function. New Phytologist 177, 608-626.

Choat B., Drayton W.D., Brodersen C., Mattthews M.A., Shackel K.A., Wada H. \& McElrone A.J. (2010) Measurement of vulnerability to water-stress induced cavitation in grapevine: a comparison of four techniques applied to a long-vesseled species. Plant, Cell \& Environment 33, 1502-1512.
Churchill G.A. \& Doerge R.W. (1994) Empirical thresholds values for quantitative trait mapping. Genetics 138, 963-971.

Cochard H. (2006) Cavitation in trees. C.R. Physique, Paris, France 7, 1018-1026.

Cochard H., Coste S., Chanson B., Guehl J.M. \& Nicolini É. (2005a) Hydraulic architecture correlates with bud organogenesis and primary shoot growth in beech (Fagus sylvatica). Tree Physiology 25, 1545-1552.

Cochard H., Damour G., Bodet C., Tharwat I., Poirier M. \& Améglio T. (2005b) Evaluation of a new centrifuge technique for rapid generation of xylem vulnerability curves. Physiologia Plantarum 124, 410-418.

Cochard H., Casella E. \& Mencuccini M. (2007) Xylem vulnerability to cavitation varies among poplar and willow clones and correlates with yield. Tree Physiology 27, 1761-1767.

Cochard H., Barigah T.S., Kleinhentz M. \& Eshel A. (2008) Is xylem cavitation resistance a relevant criterion for screening drought resistance among Prunus species? Journal of Plant Physiology 165, 976-982.

Cochard H., Hölttä T., Herbette S., Delzon S. \& Mencuccini M. (2009) New insights into the mechanisms of water-stress-induced cavitation in conifers. Plant Physiology 151, 949-954.

Cochard H., Herbette S., Barigah T., Badel E., Ennajeh M. \& Vilagrosa A. (2010) Does sample length influence the shape of xylem embolism vulnerability curves? A test with the Cavitron spinning technique. Plant, Cell \& Environment 33, 15431552.

Conner P.J., Brown S.K. \& Weeden N.F. (1998) Molecularmarker analysis of quantitative traits for growth and development in juvenile apple trees. Theory of Applied Genetics 96, $1027-1035$.

Cruiziat P., Cochard H. \& Améglio T. (2002) Hydraulic architecture of trees: main concepts and results. Annals of Forest Science 59, 723-752.

Delzon S., Douthe C., Sala A. \& Cochard H. (2010) Mechanism of water-stress induced cavitation in conifers: bordered pit structure and function support the hypothesis of seal capillaryseeding. Plant, Cell \& Environment 33, 2101-2111.

Ennajeh M., Simões F., Khemira H. \& Cochard H. (2011) How reliable is the double-ended pressure sleeve technique for assessing xylem vulnerability to cavitation in woody angiosperms? Physiologia Plantarum 139, 280-288.

Falconer D.S. (1981) Introduction to Quantitative Genetics. Longman, London, UK.

Ferreira T. \& Rasband W. (2010) The ImageJ User Guide-Version 1.43. Available at: http://rsbweb.nih.gov/ij/docs/user-guide.pdf (accessed May 2011).

Fichot R., Barigah T.S., Chamaillard S., Le Thiec D., Laurans F., Cochard H. \& Bignolas F. (2010) Common trade-offs between xylem resistance to cavitation and other physiological traits do not hold among unrelated Populus deltoides $\times$ Populus nigra hybrids. Plant, Cell \& Environment 33, 1553-1568.

Gallais A. (1990) Théorie de la selection en amelioration des plantes. Masson, Paris, France.

Gao Z.S., Van de Weg W.E., Schaart J.G., Schouten H.J., Tran D.H., Kodde L.P., Breiteneder H., Hoffmann-Sommergruber K., Bosch D. \& Gilissen L.J.W. (2005) Genomic cloning and linkage mapping of the Mal d 1 (PR-10) gene family in apple (Malus domestica). Theory of Applied Genetics 111, 171-183.

Hacke U.G., Sperry J.S., Pockman W.T., Davis S.D. \& McCulloh K. (2001) Trends in wood density and structure are linked to prevention of xylem implosion by negative pressure. Oecologia 126, 457-461.

Hacke U.G., Jacobsen A.L. \& Pratt R.B. (2009) Xylem function of arid-land shrubs from California, USA: an ecological and evolutionary analysis. Plant, Cell \& Environment 32, 1324-1333. 
Hanson W.D. (1963) Heritability. In Statistical Genetics and Plant Breeding (eds W.D. Hanson \& H.F. Robinson), pp. 125-163. National Academy of Sciences, Washington, DC, USA.

Harris S.A., Robinson J.R. \& Juniper B.E. (2002) Genetic clues to the origin of the apple. Trends in Genetics 19, 426-430.

Herbette S. \& Cochard H. (2010) Calcium is a major determinant of xylem vulnerability to cavitation. Plant Physiology 153, 19321939.

Herbette S., Wortemann R., Awad H., Huc R., Cochard H. \& Barigah T.S. (2010) Insights into xylem vulnerability to cavitation in Fagus sylvatica L.: phenotypic and environmental sources of variability. Tree Physiology 30, 1448-1455.

Hill W.G. (1971) Design and efficiency of selection experiments for estimating genetic parameters. Biometrics 27, 293-311.

Iwanami H., Moriya S. \& Abe K. (2009) Relationships between sapflow, hydraulic conductivity, and the anatomical characteristics of stems and roots in apple rootstocks of different vigour. Journal of Horticultural Science and Biotechnology 84, 632638.

Janick J. (1974) The apple in Java. HortScience 9, 13-15.

Jansen R.C. \& Stam P. (1994) High resolution of quantitative traits into multiple loci via interval mapping. Genetics 136, 1447-1455.

Jones H.G. (2007) Monitoring plant and soil water status: established and novel methods revisited and their relevance to studies of drought tolerance. Journal of Experimental Botany 58, 119130.

Kenis K. \& Keulemans J. (2007) Study of tree architecture of apple (Malus $\times$ domestica Borkh.) by QTL analysis of growth traits. Molecular Breeding 19, 193-208.

Khavkin E. \& Coe E. (1997) Mapped genomic locations for developmental functions and QTLs reflect concerted groups in maize (Zea mays L.). Theory of Applied Genetics 95, 343-352.

Kirkegaard J.A. \& Hunt J.R. (2010) Increasing productivity by matching farming system management and genotype in waterlimited environments. Journal of Experimental Botany 61, 41294143.

Knapp S.J., Stroup W.W. \& Ross W.M. (1985) Exact confidence intervals for heritability on a progeny mean basis. Crop Science 25, 192-194.

Knoblauch M. \& Peters W.S. (2010) Münch, morphology, microfluidics - our structural problem with the phloem. Plant, Cell \& Environment 33, 1439-1452.

Koch G.W. \& Sillett S.C. (2009) A response to: limitations within 'the limits to tree height'. American Journal of Botany 96, 545547.

Lauri P., Bourdel G., Trottier C. \& Cochard H. (2008) Apple shoot architecture - evidence for strong variability of bud size and composition and hydraulics within a branching zone. New Phytologist 178, 798-807.

Lemoine D., Jacquemin S. \& Granier A. (2002) Beech (Fagus sylvatica L.) branches show acclimation of xylem anatomy and hydraulic properties to increased light after thinning. Annals of Forest Science 59, 761-766.

Liebhard R., Kellerhals M., Pfammatter W., Jertmini M. \& Gessler C. (2003) Mapping quantitative physiological traits in apple (Malus $\times$ domestica Borkh. Plant Molecular Biology 52, 511-526.

Longuetaud F. \& Caraglio Y. (2009) Pith: a marker of primary growth in Picea abies (L.) Karst. Trees 23, 325-334.

Luby J.J. (2003) The apple - taxonomic classification and brief history. In Apples: Botany, Production and Uses (eds D.C. Ferree \& J.J. Warrington), pp. 1-11. CAB International, Cambridge, MA, USA

Lundström T., Heiz U., Stoffel M. \& Stöckli V. (2007) Fresh-wood bending: linking the mechanical and growth properties of a Norway spruce stem. Tree Physiology 27, 1229-1241.
Maherali H., Pockman W.T. \& Jackson R.B. (2004) Adaptive variation in the vulnerability of woody plants to xylem cavitation. Ecology 85, 2184-2199.

Maherali H., Sherrard M.E., Clifford M.H. \& Latta R.G. (2008) Leaf hydraulic conductivity and photosynthesis are genetically correlated in an annual grass. New Phytologist 180, 240247.

Maliepaard C., Alston F.H., Van Arkel G., Brown L.M., Chevreau E. \& Dunemann F. (1998) Aligning male and female linkage maps of apple (Malus pumila Mill.) using multi-allelic markers. Theory of Applied Genetics 97, 60-73.

Marcelis-van Acker C.A.M. (1994) Ontogeny of axillary buds and shoots in roses: leaf initiation and pith development. Scientia Horticulturae 57, 111-122.

Markesteijn L., Poorter L., Paz H., Sack L. \& Bongers F. (2011) Ecological differentiation in xylem cavitation resistance is associated with stem and leaf structural traits. Plant, Cell \& Environment 34, 137-148.

Parent B., Suard B., Serraj R. \& Tardieu F. (2010) Rice leaf growth and water potential are resilient to evaporative demand and soil water deficit once the effects of root system are neutralized. Plant, Cell \& Environment 33, 1256-1267.

Pratt C. (1990) Apple trees: morphology and anatomy. Horticultural Reviews 12, 265-305.

Regnard J.L., Segura V., Merveille N., Durel C.E. \& Costes E. (2009) QTL analysis for leaf gas exchange in an apple progeny grown under atmospheric constraints. Acta Horticulturae 814, 369-374.

Ripetti V., Escoute J., Verdeil J.L. \& Costes E. (2008) Shaping the shoot: the relative contribution of cell number and cell shape to variations in internode length between parent and hybrid apple trees. Journal of Experimental Botany 59, 1399-1407.

Rosell J.A. \& Olson M.E. (2007) Testing implicit assumptions regarding the age vs. size dependence of stem biomechanics using Pittocaulon (similar to Senecio) praecox (Asteraceae). American Journal of Botany 94, 161-172.

Rosner S., Klein A., Müller U. \& Karlsson B. (2007) Hydraulic and mechanical properties of young Norway spruce clones related to growth and wood structure. Tree Physiology 27, 1165-1178.

Russo S.E., Jenkins K.L., Wiser S.K., Uriarte M., Duncan R.P. \& Coomes D.A. (2010) Interspecific relationships among growth, mortality, and xylem traits of woody species from New Zealand. Functional Ecology 24, 253-262.

Sangsing K., Kasemsap P., Thanisawanyangkura S., Sangkhasila K., Gohet E., Thaler P. \& Cochard H. (2004) Xylem embolism and stomatal regulation in two rubber clones (Hevea brasiliensis Muell. Arg.). Trees 18, 109-114.

Schreiber S.G., Hacke U.G., Hamann A. \& Thomas B.R. (2011) Genetic variation of hydraulic and wood anatomical traits in hybrid poplar and trembling aspen. New Phytologist 190, 150160. doi: 10.1111/j.1469-8137.2010.03594.x

Scotti-Saintagne C., Bodénès C., Barreneche T., Bertocchi E., Plomion C. \& Kremer A. (2004) Detection of quantitative trait loci controlling bud burst and height growth in Quercus robur L. Theory of Applied Genetics 109, 1648-1659.

Scully B.T., Wallace D.H. \& Viands D.R. (1991) Heritability and correlation of biomass, growth rates, harvest index, and phenology to the yield of common beans. Journal of the American Society for Horticultural Science 116, 127-130.

Segura V., Cilas C., Laurens F. \& Costes E. (2006) Phenotyping progenies for complex architectural traits: a strategy for 1-yearold apple trees (Malus $\times$ domestica Borkh.). Tree Genetics \& Genomes 2, 140-151.

Segura V., Denance C., Durel C.E. \& Costes E. (2007) Wide range QTL analysis for complex architectural traits in a 1-year-old apple progeny. Genome 50, 159-171. 
Segura V., Cilas C. \& Costes E. (2008) Dissecting apple tree architecture into genetic, ontogenetic and environmental effects: mixed linear modelling of repeated spatial and temporal measures. New Phytologist 178, 302-314.

Sellin A., Rohejärv A. \& Rahi M. (2008) Distribution of vessel size, vessel density and xylem conducting efficiency within a crown of silver birch (Betula pendula). Trees 22, 205-216.

Solari L.I., Johnson S. \& Dejong T.M. (2006a) Relationship of water status to vegetative growth and leaf gas exchange of peach (Prunus persica) trees on different rootstocks. Tree Physiology 26, 1333-1341.

Solari L.I., Johnson S. \& Dejong T.M. (2006b) Hydraulic conductance characteristics of peach (Prunus persica) trees on different rootstocks are related to biomass production and distribution. Tree Physiology 26, 1343-1350.

Soufflet-Freslon V., Gianfranceschi L., Patocchi A. \& Durel C.E. (2008) Inheritance studies of apple scab resistance and identification of $R v i 14$, a new major gene that acts together with other broad-spectrum QTL. Genome 51, 657-667.

Sperry J.S. \& Tyree M.T. (1988) Mechanism of water stress-induced xylem embolism. Plant Physiology 88, 581-587.

Sperry J.S., Alder N.N. \& Eastlack S.E. (1993) The effect of reduced hydraulic conductance on stomatal conductance and xylem cavitation. Journal of Experimental Botany 44, 1075-1082.

Steppe K. \& Lemeur R. (2007) Effects of ring-porous and diffuse-porous stem wood anatomy on the hydraulic parameters used in a water flow and storage model. Tree Physiology 27, $43-52$.

Tombesi S., Johnson R.S., Day K.R. \& DeJong T.M. (2010) Relationships between xylem vessel characteristics, calculated axial hydraulic conductance and size-controling capacity of peach rootstocks. Annals of Botany 105, 327-331.

Tsuda M. \& Tyree M.T. (2000) Plant hydraulic conductance measured by the high pressure flow meter in crops plants. Journal of Experimental Botany 51, 823-828.

Tyree M.T. \& Ewers F.W. (1991) The hydraulic architecture of trees and other woody plants. New Phytologist 119, 345-360.

Tyree M.T. \& Sperry J.S. (1989) Vulnerability of xylem to cavitation and embolism. Annual Review Plant Physiology. Plant Molecular Biology 40, 19-38.

Tyree M.T. \& Zimmermann M.H. (2002) Xylem Structure and the Ascent of Sap 2nd edn, Springer, Berlin, Germany.
Tyree M.T., Davis S.D. \& Cochard H. (1994) Biophysical perspectives of xylem evolution: is there a trade off of hydraulic efficiency for vulnerability to dysfunction? International Association of Wood Anatomists Bulletin 15, 335-360.

Umebayashi T., Utsumi Y., Koga S., Inoue S., Matsumura J., Oda K., Fujikawa S., Arakawa K. \& Otsuki K. (2010) Xylem waterconducting patterns of 34 broad leaved evergreen trees in southern Japan. Trees 24, 571-583.

Vanderklein D., Martinez-Vilalta J., Lee S. \& Mencuccini M. (2007) Plant size, not age, regulates growth and gas exchange in grafted Scots pine trees. Tree Physiology 27, 71-79.

Van Ooijen J.W., Boer M.P., Jansen R.C. \& Maliepaard C. (2002) Map QTL 4.0: Software for the Calculation of QTL Positions on Genetic Maps. Plant Research International, Wageningen, the Netherlands.

Voorrips R.E. (2001) MapChart Version 2.0: Windows Software for the Graphical Presentation of Linkage Maps and Qtls. Plant Research International, Wageningen, the Netherlands.

Walsh B. (2001) Quantitative genetics. Encyclopedia of life sciences. Nature 1-7. Available at: http//onlinelibrary.wiley.com/ doi/10.1038/npg.els.0001785/abstract (accessed May 2011).

Webster T. (2005) The origin, distribution and genetic diversity of temprate tree fruits. In Fundamentals of Temperate Zone Tree Fruit Production (eds J. Tromp, A.D. Webster \& S.J. Wertheim), pp. 1-11. Backhuys Publishers, Leiden, the Netherlands.

Wheeler J.K., Sperry J.S., Hacke U.G. \& Hoang N. (2005) Intervessel pitting and cavitation in woody Rosaceae and other vesselled plants: a basis for a safety versus efficiency trade-off in xylem transport. Plant, Cell \& Environment 28, 800-812.

Willson C., Manos P.S. \& Jackson R.B. (2008) Hydraulic traits are influenced by phylogenetic history in the drought-resistant, invasive genus Juniperus (Cupressaceae). American Journal of Botany 95, 299-314.

Xu M. \& Korban S.S. (2002) A cluster of four receptor-like genes resides in the Vf locus that confers resistance to apple scab resistance. Genetics 162, 1995-2006.

Yao Q. \& Mehlenbacher S.A. (2000) Heritability, variance components and correlation of morphological and phenological traits in hazelnut. Plant Breeding 119, 369-381.

Received 20 December 2010; received in revised form 25 February 2011; accepted for publication 22 March 2011 